\title{
Acute sporadic hepatitis $E$ in the Zhejiang coastal area of China: a 14-year hospital- based surveillance study
}

\author{
Jun Tan', Yijuan Chen², Lin Wang ${ }^{3}$, Ta-Chien Chan ${ }^{4}$, Said Amer ${ }^{5}$, Xiaobin Xu', Jian Cai ${ }^{2}$, Wei Li ${ }^{1}$, Xiaoqing Zheng ${ }^{1}$, \\ Mi Zhou', Shuwen Qin², Na Zhao ${ }^{8}$, Ziping Miao ${ }^{2^{*}+}$ and Shelan Liü ${ }^{2^{*}+}$
}

\begin{abstract}
Background: To examine the epidemiological trends and changes of hepatitis E virus (HEV) infection and the potential risk factors for severe infection in the Zhejiang eastern coastal area of China.

Methods: We analyzed statutory hepatitis E cases notifications and inpatient data held by the national surveillance and hospital information systems in Wenzhou, Taizhou, Ningbo, and Zhoushan cities of the Zhejiang eastern coastal area of China.

Results: Nine thousand four hundred sixteen hepatitis E cases were reported from 2004 to 2017, with an average incidence of 2.94 per 100,000. The overall death rate was $0.06 \%$ (6/9416). A gradual decline of hepatitis $E$ cases was found in the coastal areas since 2007, while a rise was identified in the non-coastal areas. Annual incidence in non-coastal cities was much higher than that in coastal cities (4.345 vs. 2.945 per 100,000, relative risk $=1.5, P$ value $<0.001)$. The mean age was 52 years old and 50.55 years with a male-to-female ratio of 2.32:1 and 2.21:1 in coastal and noncoastal areas respectively (all $P>0.05$ ). Hepatitis $E$ cases prevalence increased with age, highest among men in their 70s (9.02 vs. 11.33 per 100,000) and women in their 60s (3.94 vs. 4.66 per 100,000) groups for both coastal and noncoastal areas respectively. A clear seasonal pattern was observed, with a peak in March (0.4429 per 100,000) in coastal areas. 202 inpatients were documented, of which 50.50\% (102/202) were severe cases. Male individuals with alcohol consumption, alcohol hepatic diseases, and superinfection were the three independent highest risks for severe infections (all with $P$ value $<0.05$ ).
\end{abstract}

Conclusions: This is to our knowledge the largest epidemiological study of hepatitis $E$ cases in the eastern coastal area of Zhejiang province of China. The patterns of infection across the coastal areas were similar to those of the non-coastal areas, but the incidence was substantially lower and decreased gradually since 2007.

Keywords: Hepatitis E, Epidemiology, Trends, High risks, Coastal areas

\section{Background}

Hepatitis E virus (HEV) is a non-enveloped positivesense RNA virus and the only member of the family Hepeviridae [1]. HEV strains frequently related to human infections belong to species Orthohepevirus A, in which there are 8 major genotypes (HEV1-8) [2]. To date, five

\footnotetext{
* Correspondence: zpmiao@cdc.zj.cn; liushelan20070429@126.com; liushelan@126.com

†Ziping Miao and Shelan Liu contributed equally to this work.

2Department of Infectious Diseases, Zhejiang Provincial Center for Disease Control and Prevention, 3399 Binsheng Road, Binjiang District, Hangzhou (310051), Zhejiang Province, China

Full list of author information is available at the end of the article
}

genotypes of mammalian HEV (genotypes 1-4 and 7) are known to affect humans [2,3]. HEV1 and 2 only infect humans, and are responsible for waterborne epidemics in developing regions [3], whereas zoonotic genotypes HEV3, HEV4 and HEV7 might infect human beings via foodborne transmission from different animal reservoirs (pigs and camels), but the principal reservoir is domestic pigs (HEV3 and 4), three genotypes are responsible for sporadic cases in both developed and developing countries [3-5].

Hepatitis $\mathrm{E}$ is predominantly circulating in many developing countries in Asia, Africa, and Latin America $[6,7]$, especially in countries with pig farms and coastal 
areas [8]. China is recognized as a hyperendemic area for hepatitis $\mathrm{E}[9,10]$, where a high seroprevalence has been observed among the overall population (23.46\%) [11]. The epidemiological and etiological changes have been gradually identified in China since the largest HEV outbreak in 1986 in Xinjiang Uighur autonomous region of China [12]. First of all, the predominant HEV genotype in China has changed from genotype 1 to genotype 4 [13]. Secondly, the number of hepatitis $\mathrm{E}$ cases increased, with an annual percentage change of $7 \%$ in China overall, with eastern China having the highest prevalence [14]. Thirdly, a higher health risk of hepatitis $\mathrm{E}$ cases was found in the workers who have direct contact with raw seafood or users of water and consumers of shellfish contaminated by HEV in the Bohai coastal area of China $[15,16]$. A series of articles have recorded hepatitis $\mathrm{E}$ incidence in the inlands of China, especially in rural areas [9, 10]. However, human beings infected with HEV in the coastal area of eastern China appear to be extremely limited.

This study aimed to elucidate the epidemical trends and changes as well as the related risk factors among east-coast residents in Zhejiang Province, China. We reviewed China's National Notifiable Disease Report System and hospital information systems (HIS) in four coastal cities (Wenzhou, Taizhou, Ningbo, and Zhoushan cities, Zhejiang Province) along the East China Sea, with $24,287,966$ Chinese residents, accounting for $43.45 \%$ of the general population $(55,899,795)$ in Zhejiang Province, 2017. This location is one of the most densely populated urban agglomeration areas in Zhejiang. The information extracted from this study is needed to better understand the epidemiological profile of hepatitis E cases, and will be valuable for the extensive administration of the HEV vaccine in coastal areas of China in the future. To our knowledge, this is the largest epidemiological study that has been done on hepatitis E cases in coastal areas of Zhejiang Province.

\section{Materials and methods Case definitions}

An acute viral hepatitis (AVH) case was defined as an individual having an acute illness with a discrete onset of any sign or symptom (e.g., fever, headache, malaise, anorexia, nausea, vomiting, diarrhea, or abdominal pain) and either jaundice or elevated serum alanine aminotransferase levels higher than 100 IU (United States Centers for Disease Control and Prevention, 2012). We defined hepatitis $\mathrm{E}$ cases based on the date of disease onset and on the updated diagnostic criteria issued by the Chinese Ministry of Health in 2008; these criteria are based on epidemiologic history, clinical signs, and laboratory test results [17]. Mild, moderate, and severe infections were defined according to the Child-Pugh score for grading the severity of liver disease [18, 19].

\section{Data source}

We reviewed the sporadic cases of hepatitis $E$ reported during from 2004 to 2017 from China's National Notifiable Disease Report System. We extracted the epidemic data of 9416 confirmed hepatitis E cases in four coastal cities (Taizhou, Wenzhou, Ningbo and Zhoushan) and 17,968 confirmed hepatitis E cases in seven non-coastal cities(Hangzhou, Jinhua, Quzhou, Jiaxing, Shaoxing, Lishui, and Huzhou), including the age, gender, occupation, onset date and month, outcome. The demographic information is from the China National Bureau of Statistics (with data updated by the end of each year).

A total of 202 admitted cases were included in this retrospective study during this period. All were confirmed and come randomly from the 9416 cases from coastal areas during 2004 to 2017. We also collected the following information from these inpatients from HIS in four coastal cities: age, sex, diagnosis, medical history, clinical symptoms, and biochemical indicators. The hospitals are territorial referral centers for acute hepatitis diagnosis and treatment in local cities.

\section{Laboratory testing}

All serum samples were tested for anti-hepatitis A virus (HAV), hepatitis B virus (HBV) surface antigen, and anti-hepatitis $\mathrm{C}$ virus ( $\mathrm{HCV}$ ) antibodies along with antiHEV IgG and IgM assays for the diagnosis of acute hepatitis E. All reagents for these assays were supplied by Abbott Laboratories (IL, USA) except IgM anti-HEV, which was supplied by Wan Tai Pharmaceutical Co. (Beijing, China). Routine blood investigations, including complete blood picture, coagulation profile, and liver function tests, were performed upon admission. The peak values during the time of admission to the hospital were collected.

\section{Statistical analysis}

The continuous variables are expressed as mean \pm SD. The days from clinical onset to be diagnosed, hospitalized and discharged are expressed as median $\pm \mathrm{SD}$ because they are non-normally distributed. The categorical variables are presented as the number (\%).T test and Non-parametric test was used for the continuous variables. The Chi-square test or Fisher's exact test was used to analyze the categorical variables and to assess an odds ratio(OR). To further confirm the risk factors for severe liver diseases, a multivariate logistic analysis was used for examining the variables which were found to be significant in univariate analyses or be suspected as potential risk factors from published articles [20]. All Statistical 
analyses were performed using SPSS 19.0 software (SPSS Inc., Chicago, IL). The statistical tests were two-sided, and significance was defined as $P<0.05$.

\section{Result \\ Epidemiological characteristics}

From 2004 to 2017, a total of 9416 human acute hepatitis $E$ cases were reported in the four east-coast areas of Zhejiang, accounting for $2.14-7.13 \%$ of acute hepatitis, with a case-fatality rate of $0.06 \%$ (6/9416). Figure 1a showed that the changes of the number of HEV cases in four coastal cities. The map indicated the annual cases decreased in the past 14 years except Taizhou, increased from 172 cases in 2004 to 354 cases in 2017. Figure 1b suggested the geographical distribution of HEV incidence in four cities, which Taizhou was the most affected area. The annual average cases were 673 during 2004-2017 and the annual incidence averaged 2.94 cases per 100,000 individuals from 2004 to 2017 . Since starting the disease surveillance in 2004, the incidence of hepatitis E cases in coastal areas increased slightly and peaked in 2007, with an occurrence rate of 3.98 per 100,000. Thereafter, the incidence rate gradually decreased to the lowest rate in 2013, with an incidence of 2.10 per 100,000 . The incidence started to slowly increase again starting in 2014 (Fig. 2a). By contrast, the reported rate in non-coastal areas increased quickly and reached a peak in 2011, with an incidence of 6.10 per 100,000 , sharply decreased to the lowest in 2015 , with an incidence of 3.80 per 100,000 . The yearly hepatitis E cases incidence in non-coastal cities was much higher than that in coastal cities $(4.345$ per 100,000 vs. 2.945 per 100,000, relative risk $=1.5, P$ value $<0.001$ ) (Fig. 2a).

Generally, the seasonal distribution of this pattern did not vary in different years (Fig. 2b). Cases of acute hepatitis E occurred throughout the year. However, the number of hepatitis E cases in January to May accounted for $47.29 \%$ (4453/9416) of the total cases from 2004 to 2017. Only one single peak occurred in the eastern coastal area of Zhejiang every year (Fig. 2b). As for monthly distribution, it peaked annually in March [accounting for $14.43 \%$ (1359/9416) of total cases], and the lowest incidence was identified in October [accounting for 5.39\% (507/9416)] (Fig. 2c).

The mean age of the reported cases was 52 years (range: 11 months-94 years) and 50.55 years (range: 8 months-92 years) in coastal areas and non-coastal areas respectively $(P=0.078)$. A high incidence rate was observed in the age category of 40-59 years, accounting for $45.99 \%(4330 / 9416)$ and $45.26 \%(8132 / 17968)$ of the total reported cases in coastal and non-coastal areas respectively (Fig. 3a, b). By contrast, a low incidence rate was found in children younger than 15 years old $(0.89 \%$, $84 / 9416)$ and $0.29 \%(54 / 17968)$ in coastal and non-coastal areas respectively (Fig. 3a, b). The incidence increased with age in the groups aged greater than 15 years and reached the highest point among men in their 70s $(9.02$ per 100,000$)$ and women in their 60s (3.94 per 100,000) (Fig. 3a). The same results were seen in noncoastal areas (Fig. 3b).

The overall annual incidence of hepatitis $\mathrm{E}$ cases was higher in males than in females across all age groups (2.32:1, $P<0.001)$ and $(2.21: 1, P<0.001)$ in coastal and non-coastal areas respectively. In general, there was no difference in the gender distribution between coastal and noncoastal groups $(P=0.199)$.

In occupation distribution, farmers, workers, retirees, housekeepers and businessmen together accounted for $76.96 \%(7247 / 9416)$ and $81.72 \%(14,683 / 17968)$ of total cases between coastal and noncoastal areas respectively, with a significant difference between the two groups $(P<0.001)$ (Table 1$)$. This occupational pattern was consistent year by year since 2004 in coastal and noncoastal cities.

\section{General information for HEV admitted cases}

During the study period, 202 hepatitis E confirmed inpatients were collected from the Department of Infectious Diseases or the local hepatitis reference center for diagnosis and treatment. Among these inpatients, mild, moderate and severe cases accounted for $28.22 \%$ (57/ 202), $21.28 \%(43 / 202)$, and $50.50 \%(102 / 202)$ of all inpatients respectively. The mean age was 52 years among these admitted patients, and male cases accounted for $79.21 \%(160 / 202)$.

$44.06 \%(89 / 202)$ of these inpatients were identified as having chronic liver diseases, with underlying infection with another hepatitis virus $[30.69 \%(62 / 202)]$, alcoholic liver disease [14.36\% (29/202)], and liver cirrhosis [6.93\% (14/202)] serving as important acute precipitants leading to hepatitis E cases' admission. The distribution of the various hepatitis etiological agents among these 62 hepatitis $E$ inpatients was as follows: $1.61 \%(1 / 62) \mathrm{HAV}$, 96.77\% (60/62) HBV, and $1.61 \%(1 / 62) \mathrm{HCV}$

\section{Clinical manifestation for hepatitis $\mathrm{E}$ inpatients}

The clinical presentations were as follows: Fatigue was the most frequent symptom (188 patients, 93.07\%), followed by dark urine (182 patients, $90.10 \%$ ). Jaundice was the most predominant physical examination $[84.65 \%$ $(171 / 202)]$. The alanine aminotransferase (ALT) activities varied at $42-10,038 \mathrm{IU} / \mathrm{L}$, with a peak level of 1744 IU/L. The aspartate aminotransferase (AST) activities peaked at $1453 \mathrm{IU} / \mathrm{L}$ (range: $56-8415 \mathrm{IU} / \mathrm{L}$ ) and direct bilirubin at 109 (range: 3.6-523.4) $\mu \mathrm{mol} / \mathrm{L}$. The mean prothrombin activity (PT) and albumin (ALB) at the 


\section{a}

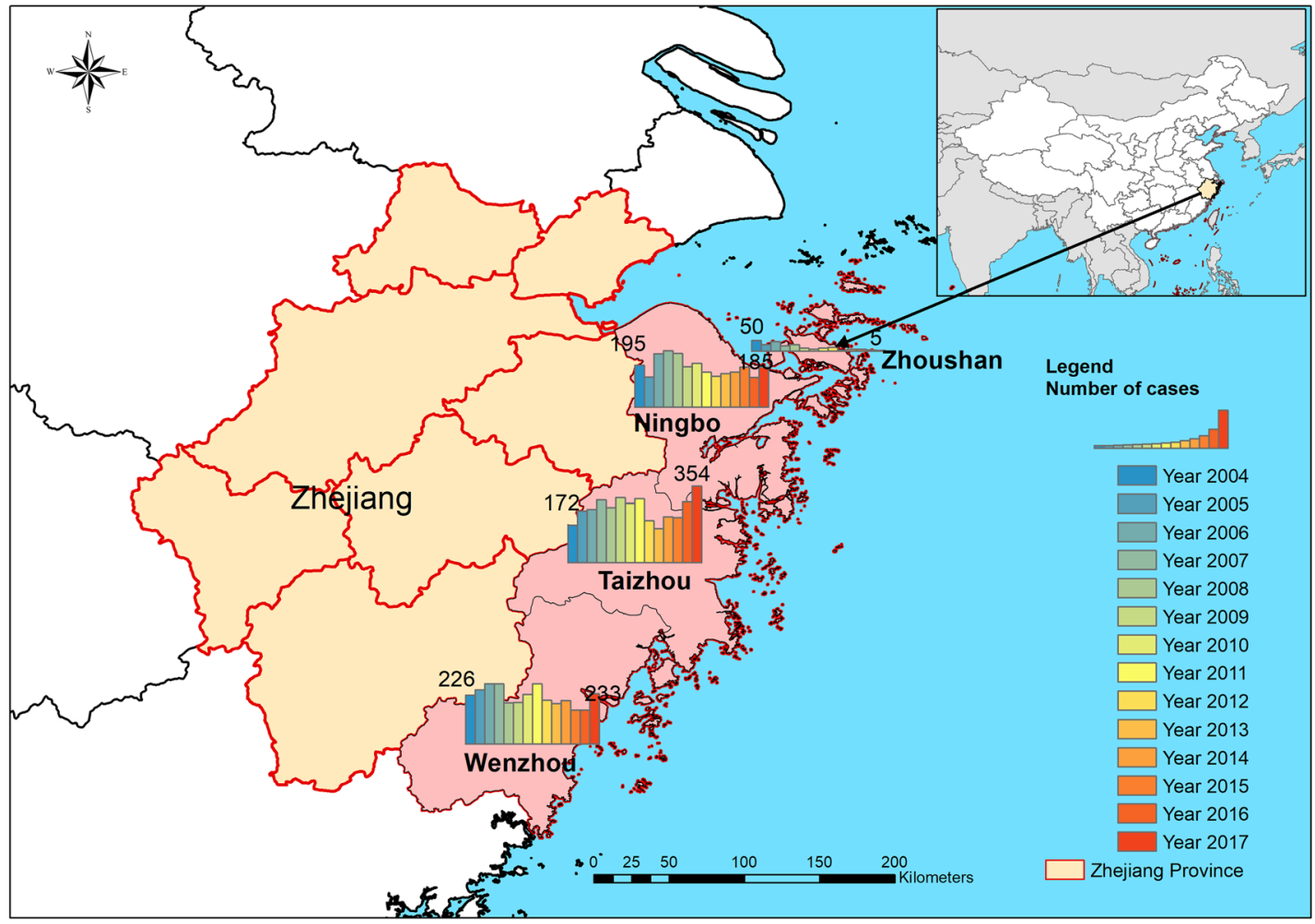

b

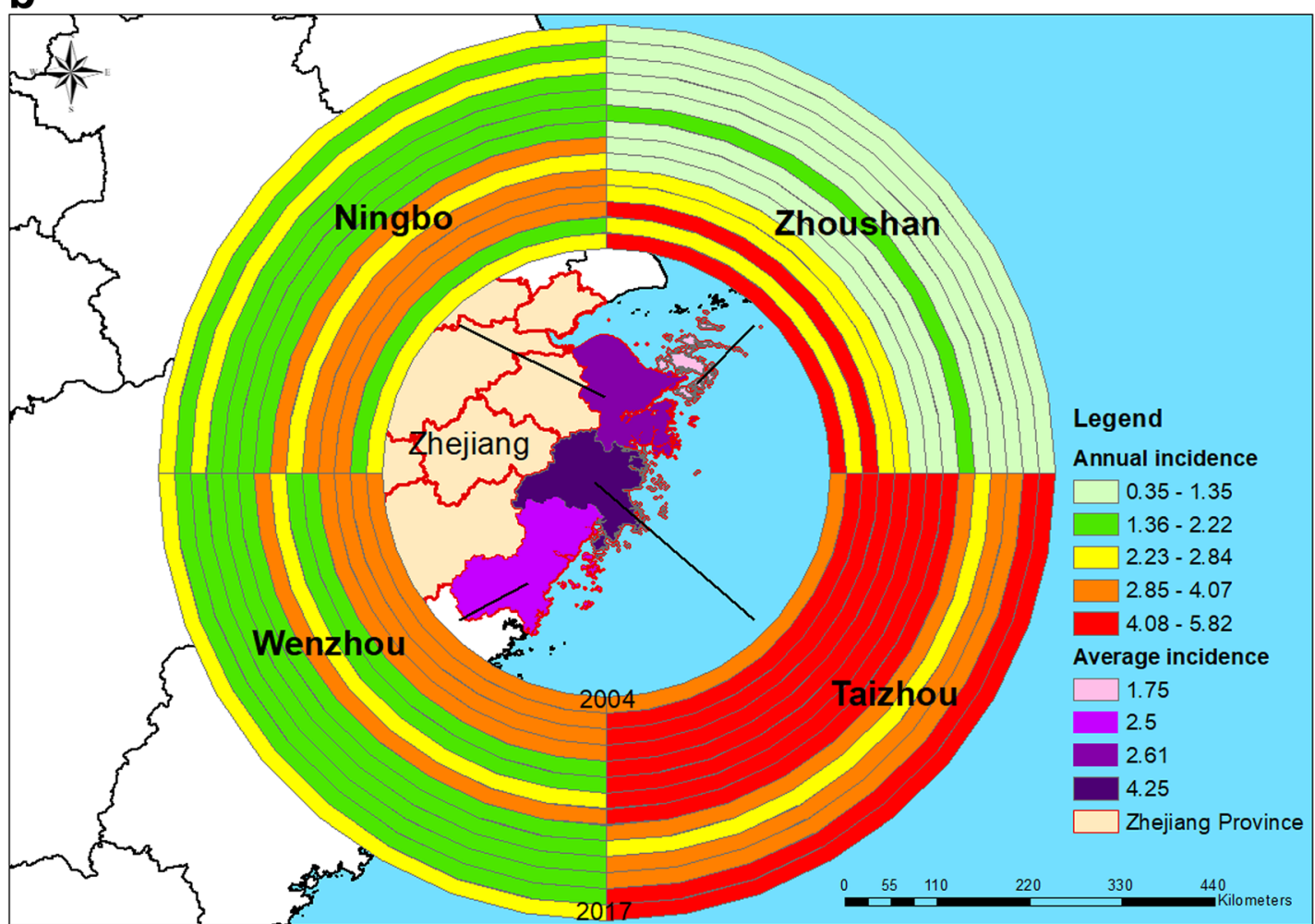

Fig. 1 Geographical distribution of human hepatitis E cases reported in east coastal areas of Zhejiang Province, China (N=9416), $2004-2017$. a: Number of cases; $\mathbf{b}$ : annual incidence and the average incidence 


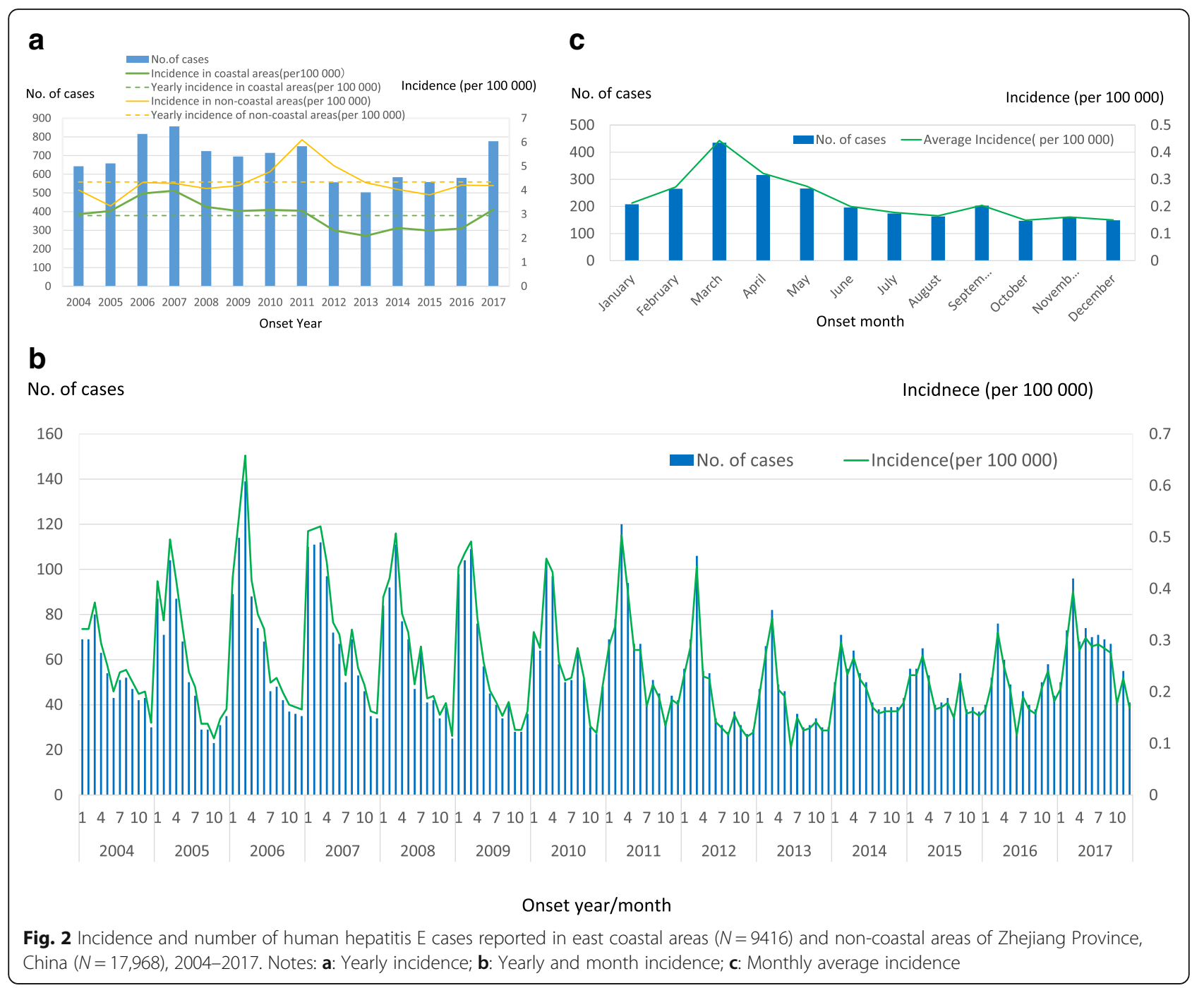

peak level were $15 \mathrm{~s}$ and $34 \mathrm{~g} / \mathrm{dL}$, respectively in those patients.

\section{The high risks of acute severe HEV infections}

We compared the epidemic features between severe and non-severe groups to find out the high risks related to the severe and super infections. The results showed that the risk leading to severe infections sharply increased in male patients, in whom alcohol consumption, frequent smoking, and alcoholic liver disease pre-existed before the time of hepatitis $\mathrm{E}$ onset (all $P$ value $<0.05$, Table 2). We further identified that the superinfection with HEV was triggered by hepatic medication and liver cirrhosis (Table 3 ).

Application of multivariate logistic regression models indicated that alcohol consumption was the only variable significantly affecting the severity of the disease (Table 4). The model estimated that odds of disease severity were mildly higher for persons with consumed alcohol than for others [odds ratio, 0.5215, 95\% CI (0.2574 1.0576), $P=0.07]$. No other covariates were significant (Table 4).

\section{Clinical process and outcome}

No differences were found between severe and non-severe cases in the median days from onset to consultation, onset to hospitalization, and onset to confirmation. However, the median days from onset to being discharged [36.5 days vs. 27 days, $P<0.001$ ] and hospital stay [26 days vs. 18 days, $P<0.001$ ] were much longer in the severe cases than in the non-severe cases (Table 2). No deaths were reported in these 202 inpatients.

\section{Discussion}

On the basis of a 14-year period of hospital surveillance, we described an ongoing decreasing trend of acute sporadic hepatitis $\mathrm{E}$ in the east-coast area of Zhejiang. Through more than 9000 confirmed hepatitis E cases, 


\section{a}

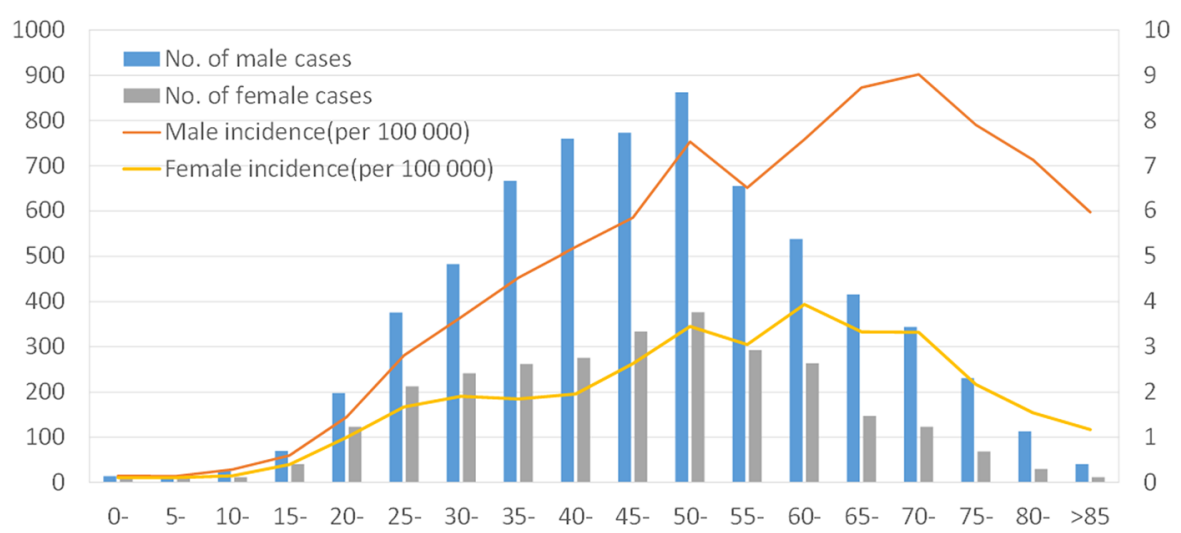

Age groups (years)

\section{b}

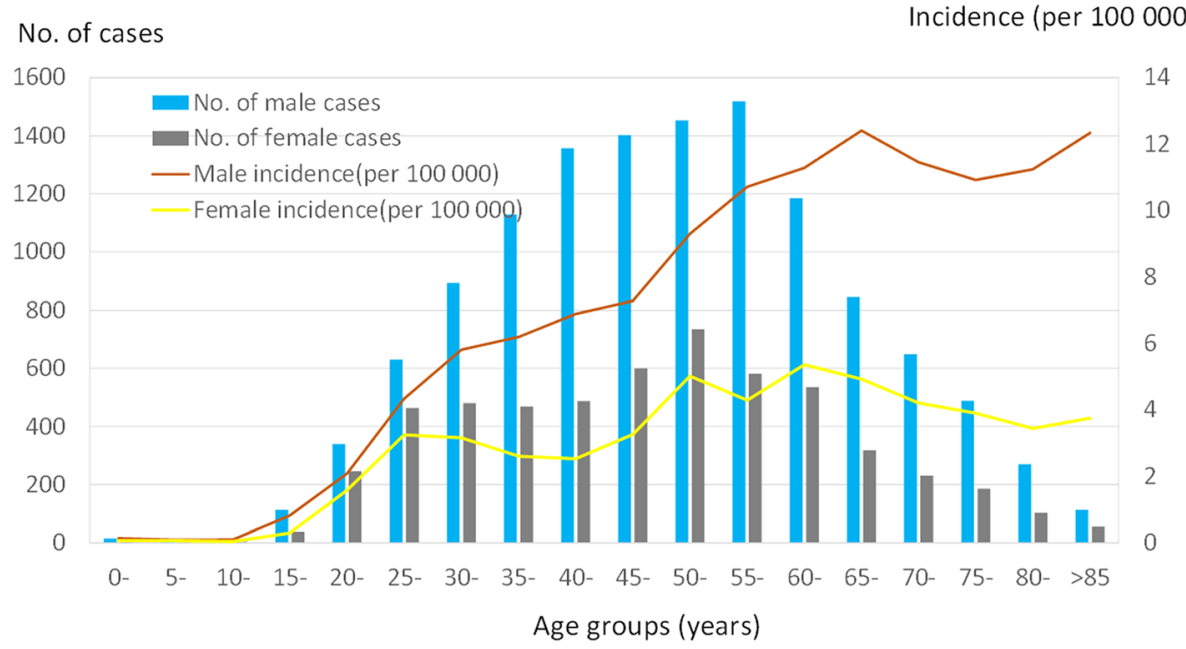

Fig. 3 Overall yearly incidence of hepatitis E cases by sex and age reported from east coastal and non-coastal areas of Zhejiang Province, China, 2004-2017. a: coastal areas $(N=9416)$; b: non-coastal areas $(N=17,968)$

this largest study discovered the epidemiological trend and changes as well as high risks for hepatitis $\mathrm{E}$ cases who lived in the developed coastal areas of Zhejiang.

This study demonstrated that the number of cases in the east-coast area of Zhejiang showed a decreasing trend since 2007. In coastal areas where swine are raised, swine manure could be a source of HEV contamination of irrigation water or coastal waters with concomitant contamination of produce or shellfish $[15,21]$. The consumption of this contaminated seafood and water may contribute to the increasing risk of zoonotic foodborne HEV circulation $[15,16]$. Our finding was in stark contrast to the experiences in the other parts of China and European countries [22-24]. For example, Jiang et al. have reported that the morbidity caused by HEV has been increasing over the recent decade and is centered on the coastal region of Yaitai of eastern China [23].
Mansuy et al. reported that the incidence of hepatitis $\mathrm{E}$ in southwest France was stable from 2003 to 2007 [24]. There may be several reasons for the decrease found in Zhejiang. First, the decrease in hepatitis $\mathrm{E}$ incidence could have resulted either from a true decrease in the number of cases or from the dominant genotype shift in China from G1 to G4 since 2000 [17, 25]. In coastal areas, seafood consumption increased from 4.15 million tons in 2004 to 4.91 million in 2015 in these areas [2016 Zhejiang Province of China Statistical Yearbook,], greater than the increase in pork consumption during that time; note that domestic pigs serve as an important reservoir for genotypes 3 and 4 [26, 27]. Second, the water supply and sanitation systems have been improved through projects to improve drinking water and lavatories by providing water pipe networks and water purification facilities as well as sewage treatment in rural areas 
Table 1 Occupational distribution of hepatitis E cases reported from east-coast and non-coastal areas of Zhejiang Province, China in 2004-2017

\begin{tabular}{|c|c|c|c|}
\hline Occupations & $\begin{array}{l}\text { Coastal areas } \\
(\%, n)\end{array}$ & $\begin{array}{l}\text { Non-coastal areas } \\
(\%, n)\end{array}$ & $P$ value \\
\hline Farmers & $44.36 \%(4177)$ & $51.76 \%(9301)$ & $P<0.001$ \\
\hline Housekeepers & $10.05 \%(946)$ & $4.04 \%(726)$ & \\
\hline Workers & $12.37 \%(1165)$ & $11.20 \%(2012)$ & \\
\hline Retirees & $5.59 \%(526)$ & $8.58 \%(1542)$ & \\
\hline Others & $6.44 \%(606)$ & $1.39 \%(249)$ & \\
\hline Officers & $3.90 \%(367)$ & $5.58 \%(1003)$ & \\
\hline Businessmen & $4.60 \%(433)$ & $6.14 \%(1103)$ & \\
\hline Migrant labor & $2.51 \%(236)$ & $2.83 \%(509)$ & \\
\hline Students & $1.67 \%(157)$ & $0.90 \%(161)$ & \\
\hline Teachers & $1.26 \%(119)$ & $1.34 \%(241)$ & \\
\hline Food industry & $0.98 \%(92)$ & $0.86 \%(154)$ & \\
\hline Fishermen & $0.63 \%(59)$ & $0.06 \%(10)$ & \\
\hline Non-nursery governess & $0.27 \%(25)$ & $0.04 \%(8)$ & \\
\hline Medical workers & $0.52 \%(49)$ & $0.65 \%(116)$ & \\
\hline Public service & $0.30 \%(28)$ & $0.21 \%(38)$ & \\
\hline Seafarers and long-distance drivers & $0.12 \%(11)$ & $0.10 \%(18)$ & \\
\hline Nursery governess & $0.04 \%(4)$ & $0.02 \%(3)$ & \\
\hline Herdsman & $0.03 \%(3)$ & $0.04 \%(7)$ & \\
\hline Nursed baby & $0.05 \%(5)$ & $0.13 \%(24)$ & \\
\hline Unknown & $4.31 \%(406)$ & $4.14 \%(743)$ & \\
\hline Total & $100 \%(9416)$ & $100 \%(17,968)$ & \\
\hline
\end{tabular}

Notes: We used the chi-square test to compare the occupational distribution between coastal and non-coastal areas of Zhejiang Province, China during 2004-2017

of Zhejiang Province in 2009 (internal data from Zhejiang Centers for Disease Control and Prevention). These steps may have decreased the transmission and infection of HEV in these areas. Third, the decrease in HEV was related to stricter regulations on large-scale swine farming and centralized slaughter in recent years, including restricting release of pollutants such as feces and sewage to the external environment, occupational protection, and HEV surveillance.

The epidemiological analysis indicated no change in the seasonal pattern or demographic features of hepatitis E cases in the past 14 years [14, 17]. Our study showed that cases of acute hepatitis E occurred regularly throughout the year during the study period, but the incidence rate was highest during March. The annual pattern was similar to those of the inland cities of China $[6,17,28]$. However, the seasonality pattern remained distinct from those in northern India and Uganda [29]. The peak time may be associated with the pattern of food preparation and excessive meat and seafood consumption that occurs during this season, which coincides with the Chinese New Year [6, 13].

The age and gender profile of infection reported in these coastal areas is in agreement with that in previous studies: Men and farmers are at great risk of acute hepatitis $\mathrm{E}$ in the inlands of China and Europe, and most are middle aged or elderly $[14,17,30,31]$. For patients aged over 50 years in particular, HEV infection increased with age. On one hand, these trends could be linked to the behavior of patients, occupational exposure, and/or broad social involvements in comparison with younger patients [13, 32]. On the other hand, HEV4 is the predominant strain among older patients in China, in comparison with epidemic HEV1 and HEV2, which predominate in young age groups [33]. These results are consistent with a study conducted in China's coastal city of Yantai [23]. Conversely, the low incidence rates and the relative paucity of laboratory-confirmed cases in pediatric populations further strengthen the hypothesis that children are unrecognized or underdiagnosed because of anicteric hepatitis or subclinical infection $[34,35]$. Asymptomatic infection is common with HEV3 and HEV4 [3, 33].

The clinical phenotypes of hepatitis $\mathrm{E}$ cases ranging from mild to fatal disease and extra-hepatic manifestation $[33,36]$ are not yet fully understood. Slightly over half of the patients (102 cases, 50.50\%) in the current study were severe when admitted to hospital. We 
Table 2 Assessment of high risks associated with disease severity among 202 acute sporadic HEV inpatients from the east- coast area of Zhejiang Province, China, 2004-2017

\begin{tabular}{|c|c|c|c|c|}
\hline Valuable & Non-severe cases $(n=100)$ & Severe cases $(n=102)$ & OR $(95 \% \mathrm{Cl})$ & $P$ value \\
\hline \multicolumn{5}{|l|}{ Demographic characteristics } \\
\hline Age range (years) & $23-80$ & $24-83$ & / & \\
\hline Mean age \pm SD (years) & $50.63 \pm 12.51$ & $51.91 \pm 13.81$ & / & $0.49^{d}$ \\
\hline Sex ratio (male/female) & $2.33(70 / 30)$ & $7.50(90 / 12)$ & $0.311(0.149-0.651)$ & $<0.01^{\mathrm{a}}$ \\
\hline Educational level (<college) $(\%, n)$ & $87.00(87 / 100)$ & $92.16(94 / 102)$ & $0.570(0.225-1.440)$ & $0.23^{\mathrm{a}}$ \\
\hline Smoker $(\%, \mathrm{n})$ & $20.00 \%(20 / 100)$ & $41.18 \%(42 / 102)$ & $2.800(1.493-5.252)$ & $<0.01^{\mathrm{a}}$ \\
\hline Alcohol user $(\%, \mathrm{n})$ & $28.00 \%(28 / 100)$ & $49.02 \%(50 / 102)$ & $2.473(1.379-4.434)$ & $<0.01^{\mathrm{a}}$ \\
\hline History of blood transfusion $(\%, n)$ & $4.00 \%(4 / 100)$ & $4.90 \%(5 / 102)$ & $1.237(0.322-4.747)$ & $1.00^{\mathrm{b}}$ \\
\hline Hepatoxic medication $(\%, n)$ & $11.00 \%(11 / 100)$ & $13.73 \%(14 / 102)$ & $1.287(0.554-2.990)$ & $0.56^{\mathrm{a}}$ \\
\hline Chronic liver diseases $(\%, n)$ & $36.00 \%(36 / 100)$ & $51.96 \%(53 / 102)$ & $1.923(1.094-3.378)$ & $0.02^{\mathrm{a}}$ \\
\hline Hepatitis A & $1.00 \%(1 / 100)$ & $0(0 / 102)$ & $0.990(0.971-1.010)$ & $0.50^{\mathrm{b}}$ \\
\hline Hepatitis B & $24.00 \%(24 / 100)$ & $35.29 \%(36 / 102)$ & $1.727(0.936-3.188)$ & $0.08^{\mathrm{a}}$ \\
\hline Hepatitis C & $1.00 \%(1 / 100)$ & $0(0 / 102)$ & $0.990(0.971-1.010)$ & $0.50^{\mathrm{b}}$ \\
\hline Liver cirrhosis & $4.00 \%(4 / 100)$ & $9.80 \%(10 / 102)$ & $2.609(0.790-8.612)$ & $0.10^{\mathrm{a}}$ \\
\hline Fatty liver disease & $4.00 \%(4 / 100)$ & $7.84 \%(8 / 102)$ & $2.043(0.595-7.012)$ & $0.25^{\mathrm{a}}$ \\
\hline Alcoholic liver disease & $9.00 \%(9 / 100)$ & $19.61 \%(20 / 102)$ & $2.466(1.063-5.720)$ & $0.03^{\mathrm{a}}$ \\
\hline Hepatic carcinoma & $1.00 \%(1 / 100)$ & $2.94 \%(3 / 102)$ & $3.000(0.307-29.337)$ & $0.62^{b}$ \\
\hline Drug-induced hepatitis & $1.00 \%(1 / 100)$ & $0.98 \%(1 / 102)$ & $0.980(0.060-15.889)$ & $1.00^{\mathrm{b}}$ \\
\hline Chronic nonliver comorbidities $(\%, \mathrm{n})$ & & & / & $0.75^{c}$ \\
\hline No comorbidities & $56.00 \%(56 / 100)$ & $60.78 \%(62 / 102)$ & / & \\
\hline 1 comorbidity & $27.00 \%(27 / 100)$ & $23.53 \%(24 / 102)$ & / & \\
\hline 2 comorbidities & $12.00 \%(12 / 100)$ & $8.82 \%(9 / 102)$ & / & \\
\hline$\geq 3$ comorbidities & $5.00 \%(5 / 100)$ & $6.86 \%(7 / 102)$ & / & \\
\hline \multicolumn{5}{|l|}{ Disease progression } \\
\hline Median days from onset to consultation & $6(0-39)$ & $6(0-24)$ & / & $0.93^{c}$ \\
\hline Median days from onset to admission & $7(1-49)$ & $7(2-38)$ & / & $0.12^{c}$ \\
\hline Median days from onset to confirmation & $11.5(4-54)$ & $11(4-43)$ & / & $0.75^{c}$ \\
\hline Median days from onset to discharge & $27(9-71)$ & $36.5(14-111)$ & / & $<0.001^{c}$ \\
\hline Days hospitalized & $18(5-46)$ & $26(7-108)$ & / & $<0.001^{c}$ \\
\hline
\end{tabular}

Notes: Non-severe cases denote mild and moderate cases; SD standard deviation, ${ }^{\mathrm{a}}=$ Chi-square test; $^{\mathrm{b}}=$ Fisher test; $^{\mathrm{c}}=$ Non-parametric test; and $^{\mathrm{d}}=\mathrm{T}_{\text {test }}$ in $P$ value column; "I" denotes not available

searched for the reasons for this disease severity, with a focus on host factors, and found that middle-aged men, especially smokers, had greater disease severity. Furthermore, alcohol consumers carried the highest risk for severe hepatitis E cases. The excessive alcohol consumption in coastal communities may play a role in the presentation of clinically overt hepatitis E infection [37]. Alcohol intake accelerates the degree of hepatic fibrosis, increases the risk of liver diseases, and worsens the clinical outcome of liver diseases [37-40]. Previous reports suggested an association between severe hepatitis infection and pre-existing diseases [41]. Indeed, $60.39 \%$ of the hepatitis $\mathrm{E}$ cases had pre-existing chronic liver diseases; among these cases, coinfection with hepatitis B virus and alcoholic liver disease were the most common. Altogether, older men who are high alcohol consumers, those with alcoholic liver disease, and HEV-superinfected individuals have a greater risk of developing severe diseases in the coastal areas of China relative to the other areas in China [13,39].

We documented 202 cases of autochthonous hepatitis $\mathrm{E}$ infection in the eastern coastal area of Zhejiang. The number of hepatitis $\mathrm{E}$ cases accounted for approximately $4.4 \%$ of AVH. Affected patients in the coastal areas have hepatic symptoms similar to those seen in the inlands of China [20]. We found $84.65 \%$ of hepatitis E cases were jaundiced at presentation. The majority of severe hepatitis $\mathrm{E}$ infections had liver derangement, of which total 
Table 3 Assessment of high risks associated with super HEV infection among 202 acute sporadic HEV inpatients from east-coast area, Zhejiang, China, 2004-2017

\begin{tabular}{|c|c|c|c|c|}
\hline Valuable & Single HEV infection $(n=141)$ & Super HEV infection $(n=61)$ & OR $(95 \% \mathrm{Cl})$ & $P$ value \\
\hline \multicolumn{5}{|l|}{ Demographic characteristics } \\
\hline Age range (years) & $23-83$ & $26-82$ & / & \\
\hline Mean age \pm SD (years) & $52.42 \pm 13.19$ & $48.64 \pm 12.84$ & / & $0.06^{\mathrm{d}}$ \\
\hline Sex ratio (male/female) & $3.55(110 / 31)$ & $4.55(50 / 11)$ & $0.781(0.363-1.677)$ & $0.53^{\mathrm{a}}$ \\
\hline Smoker $(\%, n)$ & $30.50 \%(43 / 141)$ & $31.15(19 / 61)$ & $1.031(0.538-1.974)$ & $0.93^{\mathrm{a}}$ \\
\hline Alcohol user $(\%, n)$ & $38.30 \%(54 / 141)$ & $39.34 \%(24 / 61)$ & $1.045(0.565-1.934)$ & $0.89^{a}$ \\
\hline History of blood transfusion $(\%, n)$ & $3.55 \%(5 / 141)$ & $6.56 \%(4 / 61)$ & $1.909(0.495-7.368)$ & $0.46^{\mathrm{b}}$ \\
\hline Hepatoxic medication $(\%, n)$ & $4.26 \%(6 / 141)$ & $31.15 \%(19 / 61)$ & $10.179(3.816-27.147)$ & $<0.001^{\mathrm{a}}$ \\
\hline Chronic liver diseases $(\%, \mathrm{n})$ & $19.15 \%(27 / 141)$ & $40.98 \%(25 / 61)$ & $2.932(1.515-5.767)$ & $<0.001^{\mathrm{a}}$ \\
\hline Liver cirrhosis & $2.13 \%(3 / 141)$ & $18.03 \%(11 / 61)$ & $10.120(2.712-37.768)$ & $<0.001^{\mathrm{b}}$ \\
\hline Fatty liver disease & $5.67 \%(8 / 141)$ & $6.56 \%(4 / 61)$ & $1.167(0.338-4.030)$ & $0.76^{\mathrm{b}}$ \\
\hline Alcoholic liver disease & $12.06 \%(17 / 141)$ & $19.67 \%(12 / 61)$ & $1.786(0.795-4.014)$ & $0.16^{\mathrm{a}}$ \\
\hline Hepatic carcinoma & $0.71 \%(1 / 141)$ & $4.92 \%(3 / 61)$ & $7.241(0.738-72.064)$ & $0.08^{b}$ \\
\hline Drug-induced hepatitis & $1.42 \%(2 / 141)$ & $0 \%(0 / 61)$ & / & $1.00^{\mathrm{b}}$ \\
\hline Chronic nonliver comorbidities $(\%, \mathrm{n})$ & & & / & $0.87^{c}$ \\
\hline No comorbidities & $56.74 \%(80 / 141)$ & $62.30 \%(38 / 61)$ & / & \\
\hline 1 comorbidity & $26.24 \%(37 / 141)$ & $22.95 \%(14 / 61)$ & / & \\
\hline 2 comorbidities & $11.35 \%(16 / 141)$ & $8.20 \%(5 / 61)$ & / & \\
\hline$\geq 3$ comorbidities & $5.67 \%(8 / 141)$ & $6.56 \%(4 / 61)$ & / & \\
\hline \multicolumn{5}{|l|}{ Disease progression } \\
\hline Median days from onset to consultation & $6(0-39)$ & $5(0-24)$ & / & $0.06^{c}$ \\
\hline Median days from onset to admission & $7(2-40)$ & $7(1-49)$ & / & $0.51^{c}$ \\
\hline Median days from onset to confirmation & $11(4-45)$ & $11(4-54)$ & / & $0.83^{c}$ \\
\hline Median days from onset to deterioration & $9(0-32)$ & $7(0-35)$ & / & $0.56^{c}$ \\
\hline Median days from onset to discharge & $29(9-111)$ & $33(10-73)$ & / & $0.11^{c}$ \\
\hline Days hospitalized & $21(5-108)$ & $24(6-64)$ & / & $0.15^{c}$ \\
\hline
\end{tabular}

Notes: $S D$ standard deviation; ${ }^{a}=$ Chi-square test; ${ }^{\mathrm{b}}=$ Fisher test; $^{\mathrm{c}}=$ Non-parametric test; and ${ }^{\mathrm{d}}=\mathrm{T}$ test in $P$ value column; $"$ /" denotes not available

Table 4 Multivariate logistic regression model assessing odds ratios of risk associated with severity of 202 cases caused by hepatitis E virus, from eastern coastal areas of Zhejiang Province, China, 2004-2017

\begin{tabular}{llll}
\hline Variable & Value & Odds ratio $(95 \%$ Cl) & $P$ value \\
\hline Mean Age (Years) & $52(11$ months 94 years) & $0.9990(0.9734 \sim 1.0243)$ & 0.925 \\
Gender ratio (Male/Female) & 2.59 & $1.4623(0.7033 \sim 3.0374)$ & 0.309 \\
Smoker (\%,n) & $30.69 \%(62 / 202)$ & $0.6325(0.3042 \sim 1.3152)$ & 0.22 \\
Alcohol user (\%,n) & $38.61 \%(78 / 202)$ & $0.5215(0.2574 \sim 1.0576)$ & 0.071 \\
Rural/ Urban ratio & $1.5(120 / 80)$ & $1.3526(0.6798 \sim 2.6912)$ & 0.389 \\
Chronic liver diseases, no. (\%) & $25.74 \%(52 / 202)$ & $0.7741(0.5505 \sim 1.0876)$ & 0.14 \\
Hepatic medicine (\%,n) & $12.38 \%(25 / 202)$ & $0.9176(0.3599 \sim 2.3420)$ & 0.858 \\
Median days from onset to diagnosis & $11(0 \sim 40)$ & $1.0101(0.9724 \sim 1.0492)$ & 0.618 \\
Super infection no. (\%) & $30.20 \%(61 / 202)$ & $0.5374(0.2704 \sim 1.0672)$ & 0.076 \\
Illiteracy no. (\%) & $5.45 \%(11 / 202)$ & $0.5644(0.0902 \sim 3.5325)$ & 0.541 \\
\hline
\end{tabular}


and Immunology, Institute of Microbiology, Chinese Academy of Sciences, Beijing, China.

\section{Received: 19 September 2018 Accepted: 13 January 2019 Published online: 04 February 2019}

\section{References}

1. Smith $D B$, Simmonds $P$, members of the international committee on the taxonomy of viruses Hepeviridae study G, Jameel S, Emerson SU, Harrison TJ, Meng XJ, Okamoto H, Van der Poel WH, Purdy MA. Consensus proposals for classification of the family Hepeviridae. J Gen Virol. 2015:96:1191-2.

2. WHO: Recommendations to assure the quality, safety and efficacy of recombinant hepatitis E vaccines. 2018.

3. Kamar N, Bendall R, Legrand-Abravanel F, Xia NS, ljaz S, Izopet J, Dalton HR. Hepatitis E. Lancet. 2012;379:2477-88.

4. Guillois Y, Abravanel F, Miura T, Pavio N, Vaillant V, Lhomme S, Le Guyader FS, Rose N, Le Saux JC, King LA, et al. High proportion of asymptomatic infections in an outbreak of hepatitis $E$ associated with a spit-roasted piglet, France, 2013. Clin Infect Dis. 2016;62:351-7.

5. Lee GH, Tan BH, Teo EC, Lim SG, Dan YY, Wee A, Aw PP, Zhu Y, Hibberd ML, Tan CK, et al. Chronic infection with camelid hepatitis $E$ virus in a liver transplant recipient who regularly consumes camel meat and Milk. Gastroenterology. 2016;150:355-7 e353.

6. Liu K, Cai J, Wang S, Wu Z, Li L, Jiang T, Chen B, Cai G, Jiang Z, Chen $Y$, et al. Identification of distribution characteristics and epidemic trends of hepatitis E in Zhejiang Province, China from 2007 to 2012. Sci Rep. 2016;6:25407.

7. Khuroo MS, Khuroo MS, Khuroo NS. Transmission of hepatitis E virus in developing countries. Viruses. 2016;8(9):1-20.

8. Hunter JG, Madden RG, Stone AM, Osborne N, Wheeler B, Vine L, Dickson A, Barlow M, Lewis J, Bendall RP, et al. Coastal clustering of HEV; Cornwall, UK. Eur J Gastroenterol Hepatol. 2016;28:323-7.

9. Zhu FC, Huang SJ, Wu T, Zhang XF, Wang ZZ, Ai X, Yan Q, Yang CL, Cai JP, Jiang $H M$, et al. Epidemiology of zoonotic hepatitis E: a community-based surveillance study in a rural population in China. PLoS One. 2014:9:e87154.

10. Li RC, Ge SX, Li YP, Zheng YJ, Nong Y, Guo QS, Zhang J, Ng MH, Xia NS. Seroprevalence of hepatitis $E$ virus infection, rural southern People's Republic of China. Emerg Infect Dis. 2006;12:1682-8.

11. Zhu Y, Si F, Cao D, Yu X, Yu R, Dong S, Huang F, Zhang Y, Li Z. Molecular epidemiology of hepatitis E virus infections in Shanghai. China Virol J. 2011;8:541.

12. Song DY, Zhuang H, Li Z. Hepatitis E in Hetian city. Analysis of 562 cases. Zhonghua Nei Ke Za Zhi. 1992;31:275-7 316.

13. Chen C, Zhang SY, Zhang DD, Li XY, Zhang YL, Li WX, Yan JJ, Wang M, Xun $\mathrm{JN}, \mathrm{Lu} C$, et al. Clinical features of acute hepatitis $E$ super-infections on chronic hepatitis B. World J Gastroenterol. 2016;22:10388-97.

14. Yang S, Wu J, Ding C, Cui Y, Zhou Y, Li Y, Deng M, Wang C, Xu K, Ren J, et al. Epidemiological features of and changes in incidence of infectious diseases in China in the first decade after the SARS outbreak: an observational trend study. Lancet Infect Dis. 2017;17:716-25.

15. Cui W, Sun Y, Xu A, Gao R, Gong L, Zhang L, Jiang M. Hepatitis E seroprevalence and related risk factors among seafood processing workers: a cross-sectional survey in Shandong Province, China. Int J Infect Dis. 2016 49:62-6.

16. Gao S, Li D, Zha E, Zhou T, Wang S, Yue X. Surveillance of hepatitis E virus contamination in shellfish in China. Int J Environ Res Public Health. 2015;12: 2026-36.

17. Ren X, Wu P, Wang L, Geng M, Zeng L, Zhang J, Xia N, Lai S, Dalton HR, Cowling BJ, Yu H. Changing epidemiology of hepatitis a and hepatitis $E$ viruses in China, 1990-2014. Emerg Infect Dis. 2017:23:276-9.

18. Kaplan DE, Dai F, Aytaman A, Baytarian M, Fox R, Hunt K, Knott A, Pedrosa M, Pocha C, Mehta R, et al. Development and Performance of an Algorithm to Estimate the Child-Turcotte-Pugh Score From a National Electronic Healthcare Database. Clin Gastroenterol Hepatol. 2015;13:2333-41 e2331-2336.

19. Butt AA, Ren $Y$, Lo Re V 3rd, Taddei TH, Kaplan DE. Comparing child-Pugh, MELD, and FIB-4 to predict clinical outcomes in hepatitis $C$ virus-infected persons: results from ERCHIVES. Clin Infect Dis. 2017;65:64-72.

20. Zhang S, Chen C, Peng J, Li X, Zhang D, Yan J, Zhang Y, Lu C, Xun J, Li W, et al. Investigation of underlying comorbidities as risk factors for symptomatic human hepatitis E virus infection. Aliment Pharmacol Ther. 2017:45:701-13
21. Smith JL. A review of hepatitis E virus. J Food Prot. 2001;64:572-86.

22. Aspinall EJ, Couturier E, Faber M, Said B, ljaz S, Tavoschi L, Takkinen J, Adlhoch C. Country e: Hepatitis E virus infection in Europe: surveillance and descriptive epidemiology of confirmed cases, 2005 to 2015. Euro Surveill. 2017;22(26):1-10.

23. Jiang $M$, Cui WH, Li B, Wang YL, Gong LF, Liu J. Epidemiological study on risk factors of hepatitis $E$ in Yantai, Shandong province. Zhonghua Liu Xing Bing Xue Za Zhi. 2010;31:1417-20.

24. Mansuy JM, Abravanel F, Miedouge M, Mengelle C, Merviel C, Dubois M, Kamar N, Rostaing L, Alric L, Moreau J, et al. Acute hepatitis E in south-West France over a 5-year period. J Clin Virol. 2009;44:74-7.

25. Chen YJ, Cao NX, Xie RH, Ding CX, Chen EF, Zhu HP, Sun JM, Shang XP Wang XX, Miao ZP. Epidemiological investigation of a tap water-mediated hepatitis E virus genotype 4 outbreak in Zhejiang Province, China. Epidemiol Infect. 2016:1-13.

26. Li H, Wu J, Sheng Y, Lu Q, Liu B, Chen Y, Sun Y, Zhou EM, Zhao O: Prevalence of hepatitis $E$ virus (HEV) infection in various pig farms from Shaanxi Province, China: First detection of HEV RNA in pig semen. Transbound Emerg Dis. 2018.

27. Kamar N, Izopet J, Pavio N, Aggarwal R, Labrique A, Wedemeyer H, Dalton HR. Hepatitis E virus infection. Nat Rev Dis Primers. 2017:3:17086.

28. Jia Z, Yi Y, Liu J, Cao J, Zhang Y, Tian R, Yu T, Wang H, Wang X, Su Q, et al. Epidemiology of hepatitis $E$ virus in China: results from the third National Viral Hepatitis Prevalence Survey, 2005-2006. PLoS One. 2014;9: e110837.

29. Aggarwal R. Clinical presentation of hepatitis E. Virus Res. 2011;161:15-22.

30. ljaz S, Vyse AJ, Morgan D, Pebody RG, Tedder RS, Brown D. Indigenous hepatitis E virus infection in England: more common than it seems. J Clin Virol. 2009:44:272-6.

31. Said B, ljaz S, Chand MA, Kafatos G, Tedder R, Morgan D. Hepatitis E virus in England and Wales: indigenous infection is associated with the consumption of processed pork products. Epidemiol Infect. 2014;142:1467-75.

32. Meng XJ. From barnyard to food table: the omnipresence of hepatitis $E$ virus and risk for zoonotic infection and food safety. Virus Res. 2011; 161:23-30.

33. Dalton HR, Webb GW, Norton BC, Woolson KL. Hepatitis E virus: time to change the textbooks. Dig Dis. 2016;34:308-16.

34. Chandra NS, Ojha D, Chatterjee S, Chattopadhyay D. Prevalence of hepatitis E virus infection in West Bengal, India: a hospital-based study. J Med Microbiol. 2014:63:975-80.

35. Naik SR, Aggarwal R, Salunke PN, Mehrotra NN. A large waterborne viral hepatitis E epidemic in Kanpur, India. Bull World Health Organ. 1992;70:597-604.

36. Wang L, Gao F, Lin G, Yuan Y, Huang Y, Hao H, Zhuang H, Wang L. Association of hepatitis $E$ virus infection and myasthenia gravis: a pilot study. J Hepatol. 2018:68:1318-20.

37. Dalton HR, Bendall RP, Rashid M, Ellis V, Ali R, Ramnarace R, Stableforth W, Headdon W, Abbott R, McLaughlin C, et al. Host risk factors and autochthonous hepatitis E infection. Eur J Gastroenterol Hepatol. 2011;23:1200-5.

38. Kmush $\mathrm{BL}$, Nelson $\mathrm{KE}$, Labrique $\mathrm{AB}$. Risk factors for hepatitis $\mathrm{E}$ virus infection and disease. Expert Rev Anti-Infect Ther. 2015;13:41-53.

39. Kumar Acharya S, Kumar Sharma P, Singh R, Kumar Mohanty S, Madan K, Kumar Jha J, Kumar Panda S. Hepatitis E virus (HEV) infection in patients with cirrhosis is associated with rapid decompensation and death. J Hepatol. 2007:46:387-94.

40. Junaid SA, Agina SE, Abubakar KA. Epidemiology and associated risk factors of hepatitis e virus infection in plateau state, Nigeria. Virology (Auckl). 2014; 5:15-26.

41. Borgen $K$, Herremans $T$, Duizer E, Vennema $H$, Rutjes S, Bosman A, de Roda Husman AM, Koopmans M: Non-travel related Hepatitis E virus genotype 3 infections in the Netherlands; a case series 2004-2006. BMC Infect Dis 2008, $8: 61$.

42. Monga R, Garg S, Tyagi P, Kumar N. Superimposed acute hepatitis E infection in patients with chronic liver disease. Indian J Gastroenterol. 2004;23:50-2.

43. Zhang J, Zhang XF, Huang SJ, Wu T, Hu YM, Wang ZZ, Wang H, Jiang HM, Wang YJ, Yan Q, et al. Long-term efficacy of a hepatitis E vaccine. N Engl J Med. 2015:372:914-22

44. Li SW, Zhao Q, Wu T, Chen S, Zhang J, Xia NS. The development of a recombinant hepatitis E vaccine HEV 239. Hum Vaccin Immunother. 2015; 11:908-14.

45. Labrique AB, Sikder SS, Krain $\sqcup$, West KP Jr, Christian P, Rashid M, Nelson KE. Hepatitis $E_{1}$ a vaccine-preventable cause of maternal deaths. Emerg Infect Dis. 2012;18:1401-4 